\title{
THYROGLOBULIN MEASUREMENT IN FINE-NEEDLE ASPIRATION BIOPSY OF METASTATIC LYMPH NODES AFTER rhTSH STIMULATION
}

\author{
Carlo Cappelli, MD, ${ }^{1}$ Ilenia Pirola, MD, ${ }^{1}$ Elvira De Martino, MD, ${ }^{1}$ Elena Gandossi, MD, ${ }^{1}$ \\ Elena Cimino, MD, ${ }^{1}$ Francesca Samoni, MD, ${ }^{1}$ Barbara Agosti, MD, ${ }^{1}$ Enrico Agabiti Rosei, MD, ${ }^{1}$ \\ Claudio Casella, MD, ${ }^{2}$ Maurizio Castellano, MD $^{1}$ \\ ${ }^{1}$ Department of Medical and Surgical Sciences, Internal Medicine and Endocrinology Unit, University of Brescia, Brescia, \\ Italy. E-mail: cappelli@med.unibs.it \\ ${ }^{2}$ First Division of General Surgery, University of Brescia, Brescia, Italy
}

Accepted 23 February 2011

Published online in Wiley Online Library (wileyonlinelibrary.com). DOI: 10.1002 /hed.21796

\begin{abstract}
Background. Thyroglobulin measurement in the washout of the needle used in fine-needle aspiration cytology (FNAC) has been proposed for the early detection of lymph node metastasis both in patients with or without serum thyroglobulin antibodies; however, up to now, there have been no reports that recombinant human thyrotropin (rhTSH) stimulation modifies thyroglobulin measurement in lymph node aspirates.

Methods. We described, after rhTSH stimulation, the switching from undetectable to detectable levels of thyroglobulin in fine-needle aspiration fluid from a suspected metastatic lymph node in 2 patients.

Results. We hypothesized that thyroglobulin levels in the lymph node increased after rhTSH stimulation. The excess thyroglobulin saturates all thyroglobulin antibody binding sites and becomes detectable, explaining why it was undetectable when TSH was suppressed.

Conclusion. On the basis of our experience, we suggest submitting to thyroglobulin measurement in the washout of the needle used in FNAC all patients with detectable serum thyroglobulin antibody after rhTSH stimulation. ㅇ 2011 Wiley Periodicals, Inc. Head Neck 00: 000-000, 2011
\end{abstract}

Keywords: thyroid; cancer; thyroglobulin; cytology; rhTSH

Thyroid carcinoma is the most common endocrine malignancy. Nearly $60 \%$ to $80 \%$ of new diagnoses are papillary carcinomas with excellent long-term prognosis, even though recurrences and/or metastasis mainly to cervical lymph nodes have been reported. ${ }^{1}$ The follow-up after thyroidectomy and radioiodine ablation (when appropriate) is based on basal and thyrotropinstimulated serum thyroglobulin measurement associated with neck ultrasound evaluation. ${ }^{2,3}$ Serum thyroglobulin measurement is the most sensitive and specific marker of differentiated thyroid cancer. Elevated concentrations of serum thyroglobulin are associated with the presence of residual or metastatic thyroid tissue.

Correspondence to: C. Cappelli

() 2011 Wiley Periodicals, Inc.
Nevertheless, thyroglobulin measurement does not localize neoplastic foci and, moreover, it is seriously affected by the presence of serum thyroglobulin antibodies, which may mask the presence of a recurrent or persistent thyroid carcinoma. ${ }^{4}$ Although fine-needle aspiration cytology (FNAC) represents an essential tool for detecting cervical metastasis, this technique is limited by $6 \%$ to $8 \%$ false-negative results. ${ }^{5-9}$ Thyroglobulin measurement in fine-needle aspiration fluid has been proposed for the early detection of lymph node metastasis both in patients with and without serum thyroglobulin antibodies. ${ }^{10-16}$

In a patient with high levels of serum thyroglobulin antibodies, we accidentally observed, after recombinant human thyrotropin (rhTSH) stimulation, the switching from undetectable to detectable levels of thyroglobulin in fine-needle aspiration fluid from a suspected metastatic lymph node. Once the first patient was identified, we identified another case with a high level of serum thyroglobulin antibodies in which the thyroglobulin obtained from a lymph node switched from undetectable to detectable after recombinant thyroid-stimulating hormone.

\section{PATIENTS AND METHODS}

Serum thyroid-stimulating hormone (TSH), free thyroxine (fT4), thyroglobulin and antibodies antithyroglobulin were measured using a chemiluminescent assay by an automated analyzer (Immulite 2000, DPC Cirrus, Los Angeles, CA).

The thyroglobulin assay had a functional sensitivity of $0.9 \mathrm{ng} / \mathrm{mL}$ with an analytical sensitivity of 0.2 $\mathrm{ng} / \mathrm{mL}$. The interassay variability of the thyroglobulin assay in our laboratory was $3.9 \%$.

Thyroglobulin antibodies were considered negative when less than $20 \mathrm{IU} / \mathrm{mL}$. The normal range for TSH and fT4 were 0.4 to $4.5 \mathrm{mIU} / \mathrm{L}$ and 7 to $18 \mathrm{pg} / \mathrm{mL}$, respectively. 
Table 1. Serum and Tg-FNAC assays before and after rhTSH stimulation.

\begin{tabular}{|c|c|c|c|c|}
\hline & \multicolumn{2}{|c|}{ Patient 1} & \multicolumn{2}{|c|}{ Patient 2} \\
\hline & $\begin{array}{l}\text { Before } \\
\text { rhTSH }\end{array}$ & $\begin{array}{c}\text { After } \\
\text { rhTSH }\end{array}$ & $\begin{array}{l}\text { Before } \\
\text { rhTSH }\end{array}$ & $\begin{array}{l}\text { After } \\
\text { rhTSH }\end{array}$ \\
\hline TSH, mlU/L & 0.002 & 64.3 & 0.003 & 58.9 \\
\hline $\mathrm{fT} 4, \mathrm{pg} / \mathrm{mL}$ & 10.3 & 11.6 & 17.1 & 17.8 \\
\hline Serum TgAb, IU/mL & 321 & 298 & 176 & 192 \\
\hline Serum Tg, ng/mL & $<1$ & $<1$ & $<1$ & $<1$ \\
\hline Tg-FNAC, ng/mL & $<1$ & 7.1 & $<1$ & 9.2 \\
\hline
\end{tabular}

FNAC specimens were obtained by 25 -gauge needle for capillarity under ultrasound guidance; 2 passes were performed with 2 different needles, and all the samples were performed by the same endocrinologist. The needles were washed with $0.5 \mathrm{~mL}$ of normal saline and collected in 2 tubes. The thyroglobulin values were evaluated without considering the dilution. Before the FNAC procedure, serum samples for thyroglobulin and thyroglobulin antibodies were obtained.

\section{CASE REPORTS}

Patient 1 was a 53-year-old white woman who underwent total thyroidectomy for multinodular goiter. The histology evidenced a unifocal classical papillary carcinoma in the right lobe (diameter $11 \mathrm{~mm}$ ). The patient was on suppressive therapy with levothyroxine $(125 \mathrm{mcg} /$ daily); 2 weeks before radioiodine ablation, an ultrasound investigation evidenced a cervical lymph node (diameter $6 \mathrm{~mm}$ ) suspected for metastasis in the right side of the neck. The patient underwent a serum assay for thyroglobulin, thyroglobulin antibodies, and thyroglobulin measurement in the washout of the needle used for the lymph node aspiration (Table 1). Serum thyroglobulin and thyroglobulin on fineneedle aspiration fluid were both undetectable. Seven days later, she underwent thyroid ablation with rhTSH stimulation. The patient received 1 injection of rhTSH (0.9 mg intramuscularly, Thyrogen; Genzyme Therapeutics, Cambrige, MA) for 2 consecutive days, followed by the therapeutic dose $(50 \mathrm{mCi})$ of ${ }^{131} \mathrm{I}$ 24 hours after the last injection, and by a posttherapy whole-body scintigraphy (WBS) 72 hours after ${ }^{131} \mathrm{I}$ treatments. Serum samples for TSH, thyroglobulin, and thyroglobulin antibodies measurement were collected 3 days after the last injection of rhTSH (Table 1). The WBS showed high radioiodine uptake in the thyroid bed, compatible with thyroid remnants, and doubtful uptake in the right neck side where an ultrasound scan showed the suspected lymph node, which was (re)submitted to cytology and to thyroglobulin on fine-needle aspiration fluid evaluation 2 days later. The cytological sample was suggestive of metastases and thyroglobulin was detectable $(7.1 \mathrm{ng} / \mathrm{mL})$.
Patient 2 was a 60 -year-old white woman affected by Hashimoto thyroiditis and underwent surgery for suspected papillary thyroid carcinoma at cytologic evaluation. The histology confirmed the presence of a classic papillary carcinoma (diameter $8.3 \mathrm{~mm}$ ) in the right lobe of the gland and a microcarcinoma (0.4 $\mathrm{mm}$ ) in the left lobe. She was on suppressive therapy with levothyroxine ( $150 \mathrm{mcg} /$ daily). A neck ultrasound performed 4 months after surgery showed in the right side of the neck (level III) a lymph node (diameter 8 $\mathrm{mm}$ ) suspected of recurrence that underwent thyroglobulin evaluation on fine-needle aspiration fluid; thyroglobulin was undetectable. Laboratory findings are reported in Table 1 . Ten days later, the patient underwent thyroid ablation with rhTSH stimulation, as described above. Serum samples for TSH, thyroglobulin, and thyroglobulin antibodies were collected 3 days after the last injection of rhTSH stimulation (Table 1). The WBS showed mild radioiodine uptake in the thyroid bed, compatible with thyroid remnants, and uptake in the right side of the neck where an ultrasound showed the suspected lymph node. Before the administration of therapeutic ${ }^{131} \mathrm{I}$ dose $(50 \mathrm{mCi})$, the suspected lymph node was subjected to thyroglobulin evaluation on fine-needle aspiration fluid again. Thyroglobulin assay was $9.2 \mathrm{ng} / \mathrm{mL}$.

Follow-up. Patient 1 (follow-up period 37 months) is on suppressive therapy. She was resubmitted to $\mathrm{I}^{131}$ $(50 \mathrm{mCi})$ in levothyroxine withdrawal after 1 year. The WBS was negative for recurrences. Serum thyroglobulin was undetectable and thyroglobulin antibodies were $303 \mathrm{IU} / \mathrm{mL}$.

Patient 2 (follow-up period 29 months) is on suppressive therapy. She was administered $\mathrm{I}^{131}$ (100 $\mathrm{mCi}$ ) in levothyroxine withdrawal. The WBS showed the persistence of iodine uptake in the right side of the neck, and an ultrasound confirmed the presence of the suspected lymph node. Serum thyroglobulin was undetectable and thyroglobulin antibodies were $201 \mathrm{IU} / \mathrm{mL}$.

\section{DISCUSSION}

It is well established that serum thyroglobulin measurement is a main tool for the early diagnosis of papillary thyroid cancer recurrence or metastasis, both in patients in whom TSH levels are obtained with levothyroxine withdrawal or after exogenous TSH stimulation. $^{2,3}$ The major limitation of this diagnostic procedure is the presence of detectable serum thyroglobulin antibodies, which may interfere with the serum thyroglobulin assay, ranging from false-positive to false-negative results. ${ }^{17-19}$

Thyroglobulin measurement in lymph node aspirates was first described by Pacini et $\mathrm{al}^{9}$ in 1992 to increase the diagnostic sensitivity in identifying metastasis from thyroid carcinomas in cervical lymph nodes. Since then, many other authors have adopted 
this procedure with significant results. ${ }^{14,20,21}$ Recently, a large retrospective study by Snozek et $\mathrm{al}^{22}$ showed a $100 \%$ sensitivity and a $96 \%$ specificity in detecting recurrences adopting a thyroglobulin cutoff in the washout of the needle of $1 \mathrm{ng} / \mathrm{mL}$. Similar results were also obtained in non-thyroidectomy patients with lymph nodes metastasis. ${ }^{11-13}$ The presence of serum thyroglobulin antibodies seems not to affect the results of this procedure.

In fact, Baskin ${ }^{16}$ reported in a small number of patients that there were no difference in terms of sensibility and specificity in detecting lymph node metastasis between patients with or without serum thyroglobulin antibodies. Moreover, Boi et $\mathrm{al}^{13}$ found high thyroglobulin levels in fine-needle aspiration fluid in all histologically proven metastases, independently of the serum thyroglobulin antibodies. Differently, we describe 2 patients with detectable serum thyroglobulin antibodies and suspected lymph node metastasis in whom thyroglobulin levels in lymph node aspirates became detectable after rhTSH stimulation. These observations were not due to the serum thyroglobulin antibody titers as they did not differ substantially in the 2 patients before and after rhTSH stimulation.

It has been demonstrated that thyroglobulin antibodies are found in fine-needle aspiration washout fluid from metastatic lymph nodes in at least one-quarter of patients with detectable serum thyroglobulin antibodies. ${ }^{13}$ For these reasons, it is possible that thyroglobulin antibodies in metastatic lymph nodes may fully prevent the detection of thyroglobulin in fine-needle washout fluid. One possible and intriguing explanation for this rare phenomenon could be that the exceedingly elevated thyroglobulin antibody concentration in the lymph node saturates all the thyroglobulin. Unfortunately, we did not analyze thyroglobulin antibody concentration in fineneedle washout fluid of our patients; however, we can hypothesize that thyroglobulin levels in the lymph node increased after rhTSH stimulation. The excess thyroglobulin saturates all thyroglobulin antibodies binding sites and becomes detectable, explaining why it was undetectable when TSH was suppressed.

We must underline the potential limitations of these case reports: first, the absence of histological confirmation of the suspected lymph nodes metastasis, because neither of the patients underwent surgery; and second, possible sampling error of the lymph nodes by the operator.

Even if the 2 lymph nodes submitted to fine-needle aspiration were "quite small" (6 and $8 \mathrm{~mm}$ in diameter, respectively), it should be underlined that the development of technology, particularly the ultrasound and probe, makes it possible to successfully undergo fine-needle cytology even in lesions of just 1 millimeter in diameter. ${ }^{23}$ In our patients, the samples were obtained by ultrasound guidance, well visualiz- ing the needle in the lymph nodes core by a welltrained and experienced endocrinologist (C. Cappelli ${ }^{24-27}$; for this reason we can reasonably exclude any sample error. Moreover, the 2 suspected lymph nodes showed ultrasound features (cystic appearance, loss of hilum, and hyperechoic punctuation) well known to be associated with metastasis. ${ }^{28,29}$

However, owing to the lack of histological data, we can only speculate about the presence of lymph node recurrences, even though our hypothesis is reinforced by ultrasound features of the lymph nodes and moreover by the presence of thyroglobulin in needle washout. Also, the results of WBS are in agreement with our idea.

In conclusion, we report 2 patients with detectable serum thyroglobulin antibodies in whom thyroglobulin measurements in washout fluid of fine-needle cytological aspirate of suspected metastatic lymph nodes became detectable only after rhTSH stimulation. Additional studies with larger numbers of patients are needed to confirm our observation.

\section{REFERENCES}

1. Rosai J, Carcangui ML, DeLellis RA. Tumors of the thyroid gland. In: Rosai J, Sobin LE, editors. Washington, DC: Armed Forces Institute of Pathology, 1992.

2. Pacini F, Schlumberger M, Dralle H, et al. European consensus for the management of patients with differentiated thyroid carcinoma of the follicular epithelium. Eur J Endocrinol 2006;154: 787-803.

3. American Thyroid Association (ATA) Guidelines Taskforce on Thyroid Nodules and Differentiated Thyroid Cancer, Cooper DS, Doherty GM, et al. Revised American Thyroid Association management guidelines for patients with thyroid nodules and differentiated thyroid cancer. Thyroid 2009;19:1167-1214.

4. Pacini F. Follow-up of differentiated thyroid cancer. Eur J Nucl Med Mol Imaging 2002;29 Suppl 2:492-496.

5. Franklin WA, Mariotti S, Kaplan D, DeGroot LJ. Immunofluorescence localization of thyroglobulin in metastatic thyroid cancer. Cancer 1982;50:939-945.

6. Takashima S, Sone S, Nomura N, Tomiyama N, Kobayashi T, Nakamura H. Nonpalpable lymph nodes of the neck: assessment with US and US-guided fine-needle aspiration biopsy. J Clin Ultrasound 1997;25:283-292.

7. Boland GW, Lee MJ, Mueller PR, Mayo-Smith W, Dawson SL, Simeone JF. Efficacy of sonographically guided biopsy of thyroid masses and cervical lymph nodes. AJR Am J Roentgenol 1993; 161:1053-1056.

8. Sutton RT, Reading CC, Charboneau JW, James EM, Grant CS, Hay ID. US-guided biopsy of neck masses in postoperative management of patients with thyroid cancer. Radiology 1988;168 769-772.

9. Pacini F, Fugazzola L, Lippi F, et al Detection of thyroglobulin in fine needle aspirates of nonthyroidal neck masses: a clue to the diagnosis of metastatic differentiated thyroid cancer. J Clin Endocrinol Metab 1992;74:1401-1404.

10. Borel AL, Boizel R, Faure P, et al. Significance of low levels of thyroglobulin in fine needle aspirates from cervical lymph nodes of patients with a history of differentiated thyroid cancer. Eur $\mathrm{J}$ Endocrinol 2008;158:691-698.

11. Cunha N, Rodrigues F, Curado F, et al. Thyroglobulin detection in fine-needle aspirates of cervical lymph nodes: a technique for the diagnosis of metastatic differentiated thyroid cancer. Eur J Endocrinol 2007;157:101-107.

12. Uruno T, Miyauchi A, Shimizu K, et al. Usefulness of thyroglobulin measurement in fine-needle aspiration biopsy specimens for diagnosing cervical lymph node metastasis in patients with papillary thyroid cancer. World J Surg 2005;29:483-485.

13. Boi F, Baghino G, Atzeni F, Lai ML, Faa G, Mariotti S. The diagnostic value for differentiated thyroid carcinoma metastases 
of thyroglobulin ( $\mathrm{Tg}$ ) measurement in washout fluid from fineneedle aspiration biopsy of neck lymph nodes is maintained in the presence of circulating anti-Tg antibodies. J Clin Endocrinol Metab 2006;91: 1364-1369.

14. Frasoldati A, Toschi E, Zini M, et al. Role of thyroglobulin measurement in fine-needle aspiration biopsies of cervical lymph nodes in patients with differentiated thyroid cancer. Thyroid 1999;9:105-111.

15. Frasoldati A, Pesenti M, Gallo M, Caroggio A, Salvo D, Valcavi R. Diagnosis of neck recurrences in patients with differentiated thyroid carcinoma. Cancer 2003;97:90-96.

16. Baskin HJ. Detection of recurrent papillary thyroid carcinoma by thyroglobulin assessment in the needle washout after fineneedle aspiration of suspicious lymph nodes. Thyroid 2004;14: 959-963.

17. Mariotti S, Barbesino G, Caturegli P, et al. Assay of thyroglobulin in serum with thyroglobulin autoantibodies: an unobtainable goal? J Clin Endocrinol Metab 1995;80:468-472.

18. Spencer CA, Bergoglio LM, Kazarosyan M, Fatemi S, LoPresti JS. Clinical impact of thyroglobulin (Tg) and $\mathrm{Tg}$ autoantibody method differences on the management of patients with differentiated thyroid carcinomas. J Clin Endocrinol Metab 2005;90: 5566-5575.

19. Stanojevic M, Savin S, Cvejic D, Djukic A, Jeremic M, Zivancevic Simonovic S. Comparison of the influence of thyroglobulin antibodies on serum thyroglobulin values from two different immunoassays in post surgical differentiated thyroid carcinoma patients. J Clin Lab Anal 2009;23:341-346.

20. Sigstad E, Heilo A, Paus E, et al. The usefulness of detecting thyroglobulin in fine-needle aspirates from patients with neck lesions using a sensitive thyroglobulin assay. Diagn Cytopathol 2007;35:761-767.

21. Cignarelli M, Ambrosi A, Marino A, et al. Diagnostic utility of thyroglobulin detection in fine-needle aspiration of cervical cystic metastatic lymph nodes from papillary thyroid cancer with negative cytology. Thyroid 2003;13:1163-1167.

22. Snozek CL, Chambers EP, Reading CC, et al. Serum thyroglobulin, high-resolution ultrasound, and lymph node thyroglobulin in diagnosis of differentiated thyroid carcinoma nodal metastases. J Clin Endocrinol Metab 2007;92:4278-4281.

23. Kim DW, Kim SH, Jung SJ. Successful sonography-guided fineneedle aspiration biopsy of a 1-millimiter-diameter papillary thyroid microcarcinoma. AJNR Am J Neuroradiol 2010;31:1082-1084.

24. Cappelli C, Pirola I, Gandossi E, De Martino E, Agosti B, Castellano M. Fine-needle aspiration cytology of thyroid nodule: does the needle matter? South Med J 2009;102:498-501.

25. Cappelli C. Should we use stylet needles for aspiration cytology of thyroid nodules? Nat Clin Pract Endocrinol Metab 2009;5:84-85.

26. Cappelli C, Tironi A, Pirola I, et al. Spinal needle improves diagnostic cytological specimens of thyroid nodules. J Endocrinol Invest 2008;31:25-28.

27. Cappelli C, Pirola I, Castellano M, et al. Fine needle cytology of complex thyroid nodules. Eur J Endocrinol 2007;157:529-532.

28. Fish SA, Langer JE, Mandel SJ. Sonographic imaging of thyroid nodules and cervical lymph nodes. Endocrinol Metab Clin North Am 2008;37:401-417.

29. Sohn YM, Kwak JY, Kim EK, Moon HJ, Kim SJ, Kim MJ. Diagnostic approach for evaluation of lymph node metastasis from thyroid cancer using ultrasound and fine-needle aspiration biopsy. AJR Am J Roentgenol 2010;194:38-43. 